\title{
A RECEPÇÃO DO MITO DE HÉRACLES NA ETRÚRIA POR MEIO DE UM ESTUDO DE HI- DRIAS CERETANAS
}

\section{THE RECEPTION OF THE MYTH OF HERAKLES ON ETRU- RIA THROUGH A STUDY OF CAERETAN HYDRIAI}

\author{
Nancy Maria Antonieta Braga Bomentre ${ }^{1}$
}

Resumo: Buscando uma maior compreensão da cultura etrusca, este estudo propõe verificar como foi introduzida a narrativa do mito de Héracles e como se deu sua recepção e assimilação por este povo, visto pela fruição dos objetos de arte. Os objetos específicos escolhidos para esta análise foram hidrias ceretanas, por formarem um corpus coeso e de características muito peculiares. Para tanto, partiu-se em três trajetórias distintas: uma primeira que trata de um levantamento histórico sobre a Etrúria e o contexto geral do período, uma segunda sobre a arte etrusca objetivamente e uma terceira, que contempla um estudo sobre cerâmicas do período e sua iconologia.

Palavras chave: recepção; mito de Héracles; hidrias ceretanas; arte etrusca.

Abstract: Searching a better understanding of the Etruscan culture, this study aims to verify how the myth of Heracles was introduced and how was the reception and assimilation for this people, through artistic enjoyment. A particular set of objects was chosen for this analysis: caeretans hydriai, because they set up a cohesive corpus and have very peculiar characteristics. Therefore, analyzing in three distinct ways: the first dealing with a historical survey of the Etruria and the general con-

\footnotetext{
${ }^{1}$ Graduanda do sétimo termo em História da Arte pela UNIFESP-Universidade Federal de São Paulo. Bolsista de Iniciação Científica pela Fapesp com pesquisa na área de arte antiga sob orientação o Prof. Dr. José Geraldo Costa Grillo. Lattes: lattes.cnpq.br/6400162356185324.
} 
text of the period, a second on Etruscan art objectively and a third, which includes a study of ceramics in that time and their iconology.

Keywords: reception; myth of Herakles; caeretan hydriai; Etruscan art.

\section{Introdução}

Neste texto, buscamos compreender como os etruscos receberam e qual foi o sentido que deram para o mito de Héracles, quando este foi introduzido em sua sociedade. Para tal fim, foram escolhidas como suporte do estudo, as hidrias produzidas em Caeres, pois uma considerável porcentagem do total, praticamente um quarto dos quarenta e dois vasos já encontrados, possui a representação de algum dos feitos do heroi.

A Etrúria, tal como outros povos mediterrâneos, era constituída por cidades independentes entre si. Havia em seu território- que é compreendido na região centro norte da península itálica, entre os rios Arno, ao norte e Tevere a leste- doze cidades estado principais, entre elas Caeres, que se situava ao sul do território etrusco, próximo a Roma ${ }^{2}$. A cultura etrusca se desenvolveu a partir de outro grupamento social que habitava na região, a cultura Vilanoviana, a partir do século IX a. C. Os vilanovianos habitavam em pequenas vilas e eram basicamente agricultores e mineradores. A partir do século VIII a. C., quando da chegada de povos orientais, a mescla cultural proporcionou uma melhoria nas técnicas de produção agrícola e de extração mineral, e o decorrente aumento

\footnotetext{
${ }^{2}$ No período de maior desenvolvimento da cultura etrusca, Roma ainda era apenas um vilarejo sob domínio de uma elite etrusca. Esta situação só se modificará em 509 a. C. com a expulsão do rei etrusco Tarquínio da cidade. A partir daí, a Cidade buscará escrever sua história totalmente desvinculada de sua raiz cultural etrusca. (GRIMAL, 2010)
} 
da população e crescimento das cidades. É o período em que se desenvolve uma raiz cultural propriamente etrusca. Entre os povos itálicos do período (latinos, sabinos, úmbrios, lígures, etruscos e romanos) que compreende entre os séculos VIII e IV a. C., os etruscos atingiram o maior desenvolvimento social, econômico e cultural. Posterior a isto, Roma dominará a península.

Os ritos funerários, que compreendem os cuidados com os mortos e o entendimento com o além-túmulo, são característica marcante da cultura etrusca. Na cultura vilanoviana já aparecia o gérmen dos sofisticados ritos que seriam desenvolvidos, alcançando grande requinte durante o século VI a. C., período em que foram produzidas as hidrias aqui estudadas, estas que serviam de oblação aos falecidos pelos seus familiares, depositadas nas tumbas nas necrópoles da cidade de Caeres.

A grande sofisticação encontrada na cultura etrusca é devida ao enriquecimento e prosperidade que este povo alcançou através do comércio de metais e produtos metalúrgicos que produzia. É durante os séculos VII e VI a. C. que corresponde à fase de maior desenvolvimento econômico da civilização etrusca, em razão de seu domínio no comércio de metais e marítimo, incluindo a pirataria, a chamada "talassocracia tirrenica" (PALLOTINO, 1985), como a historiografia helênica se referia aos navegadores etruscos, os quais concorriam com os gregos e os fenícios pela hegemonia do Mediterrâneo. Este intenso comércio promoveu o enriquecimento dos etruscos, primeiro de uma elite aristocrática, muito culta e refinada, e ávida pelos produtos de origem grega, que importava uma grande quantidade de peças artísticas de toda ordem para 
adornar desde sua residência até suas tumbas. $\mathrm{O}$ consumo da arte grega não era apenas uma transferência cultural. Passava pela comitência do comprador etrusco, que escolhia para si aquilo que melhor representava seus valores culturais. Muitos artistas de origem grega e oriental se estabeleceram na Etrúria para melhor atender as demandas da sofisticada clientela etrusca. Este é o caso do artista responsável pelas hidrias de Caeres. Sua origem, depois de muitos debates entre a comunidade acadêmica, foi atribuída à Focea ${ }^{3}$, uma das cidades da Ásia Menor que perdeu muitos de seus habitantes fugindo da invasão persa, e que aportaram, entre outros lugares, nas costas da Etrúria. Posteriormente, já a partir do século $\mathrm{V}$, surgiu uma classe burguesa, que buscava imitar o gosto da elite, porém adaptando e mesclando outro gosto estético às suas manifestações, mas este período foge da análise aqui pretendida, pois às hidrias é atribuída uma datação entre os anos 540 a 490 a.C.

A chegada do mito de Héracles à Etrúria se dá justamente através do artista das hidrias ceretanas (BAYET, 1926; BLOCH, 1976). Os primeiros registros de imagem do heroi na península italiana são as representações nas hidrias de Caeres, em meados do século VI a. C., encontradas em tumbas nas necrópoles da cidade. A partir de então, foi adotado como o personagem predileto dos etruscos. São inúmeras as

\footnotetext{
${ }^{3}$ A origem focea do artista é atribuída pelas características do traçado do desenho e também devido ao uso do desenho de focas, adornando as hidrias. A foca era considerada símbolo da cidade que leva seu nome, Focea, e, portanto elemento que sinaliza a origem do artista. (CAMPOREALE, 2011).
} 
representações em todos os tipos de suporte, sejam eles vasos estelas, espelhos e outros ${ }^{4}$.

O heroi grego aportou em terras etruscas com a vestimenta de deus, melhor dizendo, a percepção que os etruscos tinham de Héracles é que este já era um ser divino, prontamente divinizado pelo cumprimento de seus feitos e sua morte apoteótica. Héracles, na sua trajetória, pela sua conduta heroica, ultrapassou sua natureza puramente humana, e se tornou merecedor de um lugar no Olimpo.

\section{As hidrias de Caeres}

As hidrias são vasos cerâmicos que tem por uso o armazenamento de água, foram encontradas na sua maioria em necrópoles da cidade etrusca, foram produzidas por volta do final do século VI (540 a. C.) e o início do V (490 a. C.). São um modelo comum de vasos usados na antiguidade, mas estas produzidas em Caeres tem características próprias que as distinguem das demais de outras localidades. Por constituirem um corpus singular e de significação profunda, estes vasos já foram objetos de estudo de muitos autores, que se debruçaram sobre elas com

\footnotetext{
${ }^{4}$ Desde as primeiras escavações em contexto etrusco, no século XIX, a abundância de objetos com a representação do heroi chamou a atenção da comunidade acadêmica. Há uma grande variedade nas formas de representação, como estelas, máscaras mortuárias, espelhos, estátuas, atestando a importância do mito na sociedade etrusca, o que levou ao debate sobre como este mito era recebido nesta sociedade. Dentre os debatedores, Edmond Pottier (1892), consideravam que os etruscos eram apenas mais um dos grupamentos sociais pertencentes ao mundo e cultura gregos e sua forma de recepção não variava dos outros povos. Jean Bayet (1927) e Nicolas Plautine (1942) defenderam uma visão autêntica e própria dos etruscos quanto à narrativa mitológica nas representações apresentadas nos objetos dispostos em ambiente funerário.
} 
objetivo de esclarecer tanto aspectos formais como iconológicos. Dois dos mais significativos estudos sobre a forma das hidrias, que tiveram o objetivo de estabelecer autoria são os catálogos de V. Callipolitis, de 1954 e J. M. Hemelrijk, de 1956 (este posteriormente republicado em 1984). Em 2008, Raffaella Bonaudo (BONAUDO, 2008) publicou um estudo iconológico sobre quarenta hidrias, baseando-se no catálogo de Hemelrijk. Seu estudo, diferentemente dos dois primeiros citados, não tem como escopo atribuir autoria dos vasos. Atualmente, já se tem praticamente como consenso que o autor dos vasos era um artista de origem grega estabelecido na Etrúria. Pelo estudo dos vasos, da técnica, distribuição de cores e estilo chegou-se ao nome do Pintor de Águia e que teve como auxiliar o chamado Pintor de Busíris. A origem precisa destes artistas não é possível assegurar. Alguns autores dão como procedência focea (CAMPOREALE, 2011), outros, jônica (SANTANGELO, 1950). No final do século XIX, Edmond Pottier afirmou que a origem do artista era Clazomene, ou outra cidade próxima na Ásia Menor, devido à semelhança da pintura das hidrias com a técnica e o traçado encontrado em sarcófagos clazomenos. Pottier julgava que mesmo o atelier onde foram produzidos era asiático, sendo os vasos exportados para Etrúria posteriormente, durante o período de grande prosperidade etrusca, no qual o destino de boa parte da produção cerâmica feita no mundo Mediterrâneo era este país. A controvérsia quanto à produção e origem de artefatos artísticos escavados na Etrúria remonta ao século XVIII, quando o historiador da arte J. Winkelman, grande admirador da arte grega, atribuía aos gregos a criação de qualquer peça de melhor composição, acreditan- 
do não ser possível aos etruscos- ao seu julgamento um povo tosco- o fabrico de peças sofisticadas. Ainda no inicio do século XX seguia-se este raciocínio, como o historiador e arqueólogo Rannucio Bianchi Bandinelli que somente nos seus escritos mais tardios passou a avaliar a cultura etrusca de forma mais flexível. A mudança de critérios para observação de diferentes culturas ocorreu com o advento dos estudos de sociologia e antropologia, onde estas passaram a ser observadas dentro de seus próprios critérios, sem tomar como referência o padrão estético uma determinada manifestação cultural proeminente. (BANDINELLI, 2013).

A obra de Raffaella Bonaudo parte do princípio que o artista que executou as representações nas cerâmicas era um profundo conhecedor da poesia e literatura gregas, e baseou seu trabalho numas das diversas versões dos mitos que circulavam nas sociedades mediterrâneas. Este é o mesmo entendimento de Nicolas Plaoutine no estudo "La reprèsentation de Thersite par le peintre des hydries de Caeré et les sources littéraries qui ont inspire cet artiste", de 1942, onde o autor analisa as representações baseado nas obras literárias de, principalmente, Estesícoro, Homero e Esopo, obras nas quais tem no desenrolar das suas narrativas elementos que simbolizam costumes e valores das sociedades de então, que regiam as relações sociais do "mundo dos vivos". Bonaudo, valendo-se desta linha de pensamento, desenvolve seu estudo esclarecendo as relações sociais vigentes nas sociedades do mundo mediterrâneo. (PLAOUTINE, 1942). 
Quanto às representações do mito de Héracles, apontamos aqui que esta é a narrativa apresentada no maior número de hidrias, dez exemplares, e, devemos salientar que este mito guarda em si algumas particularidades quando da sua chegada à Etrúria. $\mathrm{O}$ historiador francês Raymond Bloch atribui ao artista das hidrias a introdução do mito na Etrúria. (BLOCH, 1976, p. 47). Nesta cultura, o heroi ganhou o status de deus. Jean Bayet, (BAYET, 1974) professor de Língua e Literatura Clássicas da Sorbonne e diretor da Escola Francesa de Roma, tem, entre seus vários estudos, uma tese sobre a recepção do mito de Héracles na península itálica e, sendo um em particular, do mito na Etrúria, na qual analisa representações do heroi em ambiente funerário, sejam elas em estelas, pinturas parietais, espelhos, etc. $\mathrm{O}$ estudioso indica que dada às particularidades históricas e de formação social da Etrúria o mito não poderia simplesmente ser importado da Grécia, seu país de origem, para Etrúria sem experimentar transformações na sua recepção. A própria condição de deus que adquiriu ao aportar em terras italianas já demonstra as modificações na narrativa, que nada mais faziam que do atender o gosto e o entendimento do mito no local. Este é o escopo do estudo aqui em andamento. Buscar algumas características próprias que o mito de Héracles tomou ao ser adotado como ídolo máximo entre os itálicos, na tentativa de ir um pouco além dos aspectos simbólicos gerais de significado social apresentados por Bonaudo no seu estudo. Para tanto, o estudo iconológico das representações do mito sobre as cerâmicas se dará buscando nas obras de Jean Bayet, Raymond Bloch e de Georges Dumézil, nas quais encontramos elementos característicos específicos da 
mitologia na cultura etrusca, o embasamento para investigar a acolhida do heroi pelos etruscos. A obra de Pierre Grimal oferece a base de informações e entendimento da mitologia grega.

Os etruscos foram ávidos consumidores de produtos gregos. A cerâmica principalmente era muito apreciada. As hidrias ceretanas tem como período de produção as últimas décadas do século VI a. C. Este período corresponde à fase de maior desenvolvimento econômico da civilização etrusca, em razão de seu domínio no comércio de metais e marítimo. A invasão persa da Ásia Menor foi razão para imigração ocorrida em meados deste século em direção ao Ocidente. Acompanhando o desenvolvimento econômico, este foi o período de apogeu artístico da cultura etrusca. O contato com os povos da Ásia Menor favoreceu na arte o emprego de formas curvilíneas, do movimento, da sutileza, que são característicos na arte jônica.

Não obstante sua função regular de armazenar água e seu uso nos simpósios, estas hidrias de Caeres faziam parte de um contexto funerário. A civilização etrusca se caracterizava no seu ápice pelo primoroso cuidado com seus mortos e preservação de sua memória. As tumbas etruscas, por ser um duplo das moradias dos viventes, são legado precioso para o entendimento da complexidade e sofisticação desta cultura. No final da Idade do Bronze até o século VIII, a civilização etrusca se desenvolveu a partir da civilização vilanoviana que ocupava a região centro norte da península italiana. Esta era uma civilização basicamente agrária e mineradora e a população se agrupava em pequenos povoamentos. A intensificação da atividade mineradora proporcionou aperfei- 
çoamento nas técnicas agrícolas, levando a um aumento dos grupamentos populacionais (CAMPOREALE, 2011). Estes grupos já conferiam aos seus mortos rituais funerários que consistiam em enterramentos feitos em vasos bicônicos com decoração geométrica onde eram depostos os restos incinerados e objetos pertencentes ao morto, colocados em tumbas diretamente abertas no solo, que eram demarcadas por pedras dispostas em círculo e ainda assinaladas por seixos ao centro deste. Os objetos depostos tinham como função ser uma oblação ao falecido. Indicavam o sexo (como escudos, elmos e espadas para os homens e broches e colares para as mulheres) e também a classe social que pertencia o morto de acordo com a opulência das oferendas apresentadas. O influxo de gregos e outros povos vindos do Oriente, juntamente com a maior circulação pelo mar, proporcionou uma "orientalização" do povo vilanoviano (PALLOTINO, 1985), que ganha maior sofisticação nas suas manifestações culturais e artesanato. Durante os séculos VII e VI, os sítios urbanos se transformaram com as primeiras construções arquitetônicas e se desenvolvem como uma urbis estruturada. A estrutura de administração das cidades já está seccionada e algumas delas já possuem projeto com traçado perpendicular orientado pelos pontos cardinais, como a cidade de Marzabotto, ao norte, projeto urbano que será copiado pelos romanos posteriormente para construção de suas cidades (CIATTINI, MELANI, NICOSIA, 1971). Há um incremento nas técnicas de produção de artefatos e da atividade manufatureira. Surgem também os primeiros registros em linguagem escrita, que deriva de uma língua não indo-europeia, o que impossibilita sua interpretação até hoje. 
O ritual funerário ganhou maior complexidade, e as sepulturas tornaram-se monumentais. Construídas na periferia das cidades, as necrópoles comportavam dezenas de tumbas escavadas na rocha destinadas a uma mesma família e altares para os ritos funerários entrecortados por ruas de acesso. As tumbas eram construídas semelhantes às moradias, compostas de câmaras ricamente decoradas destinadas a oferendas e deposição dos restos do falecido. O mobiliário que compunha as câmaras- trono, cadeiras altares- era escavado na rocha. As paredes recebiam pintura ornamental com temas mitológicos e objetos de uso pessoal (como armamentos) e também utensílios de uso em banquetes. Recipientes estes produzidos em cerâmica e bronze. A estatuária é igualmente encontrada. Dois importantes aspectos da cultura etrusca podem ser revelados através do estudo da composição das tumbas nas necrópoles: tanto traços da vida doméstica em razão da similaridade com o ambiente familiar, o mundo dos vivos, como sua interpretação sobre a morte, o mundo dos mortos. Mauro Cristofani (CRISTOFANI, 1978: 68) referese ao conteúdo simbólico presente não apenas como culto aos mortos, mas como uma celebração da vida, pois assegura através da reprodução do ambiente doméstico a manutenção da conexão entre o falecido e sua integridade psicofísica. Esta é garantida pelos objetos ofertados que lhe pertenciam, os quais lhe fazem referência, como as estátuas que encimam os esquifes fazendo às vezes de retratos dos mortos, preservando a relação deste falecido com sua categoria social e protegendo o status dos descendentes. A continuação da vida está assegurada pela verossimilhança arquitetônica com as moradias e pelos objetos pessoais, trazendo 
marcas simbólicas que o identificam possibilitando sua rememoração física, tal qual como quando vivia. A manutenção da vida está ainda assegurada pelas oferendas de alimentos que compõe um cenário de simpósio.

Ainda pode-se aferir através do estudo dos ambientes funerários como era organizada a atividade dos artesãos e artistas que trabalhavam na elaboração das tumbas. Como aponta Cristofani (CRISTOFANI, 1978: 69), até o século VII a. C. não se pode assegurar o emprego de artistas que se dedicavam exclusivamente à arte funerária. Como no caso da tumba de Campana, na Necrópole de Sorbo, onde a pintura parietal se difere das pinturas nas tumbas de Caeres, na qual é tratada de modo localizado, como decoração de um espaço limitado. Na tumba de Campana, toda a execução da pintura se organiza através da mesma técnica de disposição dos elementos compositivos empregada na decoração das cerâmicas, pelo uso de elementos de decoração floral e animal, de clara influência orientalizante e coríntia, ordenados acima e abaixo de uma zona figurada principal. Destaca-se ainda o uso pronunciado de cores, criando um cenário ímpar na produção parietal, que, ao mesmo tempo se assemelha muito à produção cerâmica de igual período na região mais ao sul do território etrusco. Desta forma, pode-se entender que a atividade artesanal não se limitava a determinado segmento, cabendo aos artistas empreenderem-se em diversas atividades.

Caeres teve seu apogeu no período compreendido entre o final do século VII até o século IV a. C. graças a uma forte indústria metalúrgica provida pelos recursos naturais da região e à sua produção agrícola. A 
zona urbana da cidade era cercada por quatro necrópoles. As duas mais antigas, ao norte, de Pozzolana, e ao sul, de Sorbo, com registros tumulares que remontam o século IX. Os enterramentos eram feitos por incineração, com vasos bicônicos muitas das vezes encimados por capacetes metálicos, seguindo os rituais usuais que caracterizam a cultura etrusca até o final do século VIII. Neste período começam a aparecer as primeiras câmeras funerárias. As necrópoles mais recentes, com câmeras em parte escavadas na rocha e em parte construídas, eram arrematadas por construção tumular de aspecto monumental. Segue este modelo a $\mathrm{Ne}$ crópole de Monte Abatone, a leste de Caeres e também a importante Necrópole de Banditaccia, a oeste da cidade. Esta necrópole onde se localizam as tumbas melhor conservadas e de maior interesse arqueológico e onde foram encontradas grande parte das hidrias aqui estudadas.

\section{Héracles e o cão Cérbero}

Poder-se-ia até dizer que o mito de Héracles não é apenas um devido às inúmeras versões que circularam ao longo dos séculos no vasto território mediterrâneo. Há inúmeras versões e histórias paralelas que sabemos que circulavam pelo compreendido mundo grego. Pierre Grimal, no Dicionário de Mitologia Grega e Romana, usa a classificação tradicional dos mitógrafos antigos para dar um corpo homogêneo à narrativa, separando em três grandes ciclos: 1) o ciclo dos doze trabalhos; 2) as façanhas independentes do ciclo antecedente e 3) aventuras secundárias que aconteceram no decorrer dos doze trabalhos. (GRIMAL, 1992). 
O embate entre Héracles e o cão Cérbero pertence ao ciclo dos doze trabalhos. É a décima primeira façanha a ser cumprida pelo heroi a mando de Euristeu, o rei de Micenas, seu primo, ao qual teve que se submeter por doze anos. Após um acesso de loucura temporário provocado pela deusa Hera, Héracles matou seus filhos com Megara. Depois de recobrar a sanidade, arrependido, vai ao oráculo de Delfos perguntar à Pítia o que fazer para sua remissão. Esta o aconselha a servir o rei de Micenas, desta forma alcançaria o perdão divino. Assim, se inicia o ciclo dos doze trabalhos impostos ao heroi. Euristeu nos é apresentado como um poço de desvirtudes, entre elas a covardia, que o levou a mandar fundir um pithos de bronze de enorme proporção para se refugiar dentro caso fosse atacado por Héracles.

Neste trabalho, Héracles foi ordenado seguir ao reino de Hades para buscar o cão de três cabeças que guarda os portões. Este impede que os vivos entrem e a saída dos que lá já se encontram. O cão, filho de Equidna e Tífon, além de tricéfalo, tem o corpo coberto por serpentes. Para cumprir tal façanha, o heroi recebe ajuda de Hermes e Atena, enviados por seu pai, Zeus. Já adentrando o reino de Hades, no seu percurso para capturar o cão, Héracles encontra personagens ligados à sua narrativa, mas que não tem ligação direta com a façanha a ser cumprida. Estes personagens solicitam a intervenção do heroi em suas gestas, fazendo assim completar o curso simbólico de descida aos infernos. A condição que Hades impôs ao heroi para levar seu cão para o reino dos vivos era que a captura fosse feita sem o uso de qualquer arma. Héracles usou somente de sua força descomunal para submeter o monstro, levando-o à 
presença de Euristeu. O rei de Micenas recorreu ao seu pithos gigante para se proteger, tanto do cão como de Héracles. Este, sem saber o que fazer com o animal, devolveu-o ao senhor do submundo.

A narrativa mitológica de Héracles é apresentada em dez hidrias ceretanas. $\mathrm{O}$ embate com o cão Cérbero é mostrado em duas delas. Esta representação tem um paralelo com a aventura do javali de Eurimanto, que, da mesma forma, o heroi deveria levar o animal capturado vivo para Euristeu, e, este, por sua vez, esconde-se dentro do píthos. Não temos registro de nenhuma hidria com a representação da façanha com o javali. As hidrias com representação do heroi tem por temas o leão de Neméia, a captura de Cérbero e os embates com: o centauro Nessos e com o centauro Folo, com o gigante Alcioneu, com a Hidra de Lerna e com o faraó egípcio Busíris. Há outra hidria ceretana com a representação de um heroi lutando com o monstro marinho Ketos, que para alguns autores, como Rafaella Bonaudo, é Héracles. Devido à forma como o heroi é representado, com alguns atributos de Héracles, a hidria entra no corpus de seus feitos, mas poderia ser atribuída também ao heroi Perseu, que combate o monstro para salvar a princesa Andrômeda. (BONAUDO, 2008).

Quanto à simbologia desta narrativa de Héracles na descida ao submundo podemos levantar alguns aspectos. Héracles é o heroi por excelência e alcançou a imortalidade como recompensa de sua trajetória inspiradora como defensor da virtude. Na cultura etrusca, o heroi está intimamente ligado ao contexto funerário, devendo-se lembrar de todo o acervo artístico encontrado nas tumbas etruscas com representação do 
heroi. Os etruscos faziam de suas necrópoles e tumbas ambientes semelhantes às suas casas, onde recebiam decoração parietal e a disposição de objetos de uso cotidiano e pessoal, para marcar as preferências e status dos falecidos. A escolha por determinados mitos e símbolos para adornar os túmulos demonstram não apenas o gosto pessoal do comitente, mas também seu valor simbólico na sociedade. A preferência por um heroi que cumpre seu destino, triunfando sobre a morte, como na descida ao Hades para buscar o cão, reflete a vontade de se triunfar sobre a morte, ganhar a imortalidade no além.

Jean Bayet discorreu sobre a simbologia do mito de Héracles em contexto funerário (BAYET, 1974) tratando dos diversos temas em que o heroi é apresentado e sua significância dentro da cultura etrusca. Quanto à façanha de descida aos infernos para capturar o cão Cérbero, reforça o sentido simbólico do caminho iniciático daquele que vence a morte, retornando do submundo, triunfante. Para Bayet, ao escolher a representação de um heroi que percorre o caminho inverso da morte, sobrepujando-a, o comitente etrusco buscava para si a força de triunfar no Além. Giovannangelo Camporeale, em Gli Etruschi, aponta o aspecto de protetor dos comerciantes e das propriedades que Héracles recebeu em terras latinas, tornando-se a divindade tutelar preferida dos etruscos, levando em conta que a origem da riqueza e do crescimento social e econômico desta sociedade se baseava principalmente no comércio. (CAMPOREALE, 2011). Já Bonaudo desenvolve seu estudo esclarecendo as relações sociais vigentes nas sociedades do mundo mediterrâneo, dando ênfase no aspecto de Héracles como guardião dos costumes 
sociais e do comportamento virtuoso, sendo tomado como exemplo para a formação dos jovens.

Algumas pequenas diferenças na composição do desenho no friso principal marcam as duas hidrias que recebem a narrativa do embate entre Héracles e o cão que guarda o submundo, Cérbero.

Na composição da hidria pertencente ao acervo do Museu do Louvre (E 701), o heroi apresenta-se de pé, levando o cão por uma espécie de coleira que segura com sua mão esquerda, indicando que o traz sob seu comando. Na direita, porta sua arma mais característica, a clava. O heroi vem vestido de uma túnica encimada pela capa feita da pele do Leão de Neméia, que derrotou quando do seu primeiro feito. O cão guardião dos Infernos exibe ferocidade pelas bocarras escancaradas, mostrando os dentes. O cão de três cabeças, que foram pintadas com cores diversas, filho de Equidna e Tífon, possui o corpo recoberto por serpentes, que são mostradas ao seu redor. Euristeu, por sua vez, é apresentado dentro de seu píthos de bronze, que mandou construir para se proteger do heroi. Apresenta-se de pé com expressão assustada e os braços levantados em posição de súplica, e podemos ver quase todo seu tronco. Para compor seus longos cabelos e barbas foram feitas incisões no verniz preto. $\mathrm{O}$ uso de cores é abundante assim como os elementos decorativos que compõe a peça, como é usual nos vasos etruscos, indicando o gosto particular dos comitentes da península.

Já na hidria que pertence à Coleção do museu de Villa Giulia (50649), em Roma, a cena é composta com o heroi apresentando o cão para Euristeu apoiado no seu joelho esquerdo. Traz a clava em sua mão 
direita e a capa de leão sobre a cabeça. Um número menor de serpentes é mostrado em volta das cabeças do cão. O píthos onde o rei de Micenas se esconde tem a forma mais atarracada que o exemplar do Museu do Louvre, e, Euristeu é retratado apenas com os ombros, peito e os braços para fora. O semblante é menos assustado e os braços acompanham a expressão. Os cabelos são longos e na barba não há incisões no verniz. $\mathrm{O}$ recurso de mostrar o heroi de joelhos e o rei mais escondido dentro da jarra figura como solução para o espaço menor do friso- 13,2 cm- comparado com o vaso do museu francês, $16 \mathrm{~cm}$, apesar da hidria de Villa Giulia ter uma altura maior $(44 \mathrm{~cm})$ que o do Louvre $(42 \mathrm{~cm})$.

Em ambos os vasos, a imagem que compõe o lado oposto do friso principal possui seres alados. No vaso do Louvre, duas águias em voo caçando uma lebre e no vaso de Roma, dois cavalos alados contrapostos. Vale lembrar aqui a marca simbólica da morte e do além para os etruscos é apresentada como um demônio alado.

No vaso romano, o friso inferior ocupa uma area maior, denotando a importância que a decoração floral tinha para o gosto etrusco. A ornamentação secundária das hidrias produzidas em Caeres é ricamente composta, apresentando diversos elementos diferentes numa mesma peça, como palmetas (estas sempre presentes sob as alças e por vezes também compondo a decoração dos frisos de alguns vasos), flores de lótus, meandros, guirlandas de flores e folhas, estrelas, linguetas. $\mathrm{O}$ uso variado de cores é também característico. Estas características particulares de gosto na ornamentação da arte etrusca podem ser tomadas como um aspecto decorrente da formação desta cultura, que absorveu elemen- 
tos de outros povos advindos principalmente do oriente próximo, e que influenciaram seus modos de fazer a arte, porém sem corromper sua essência e raiz genuinamente etruscas.

\section{Considerações finais}

Mesmo pertencendo ao assim chamado "mundo grego", os etruscos pela sua formação histórica e constituição cultural, possuíam entendimento próprio dos mitos que circulavam pelo Mediterrâneo. A leitura dos registros imagéticos encontrados nas tumbas etruscas com o viés puramente funcionalista, esboçando apenas a relação do mito de Héracles com o mundo dos vivos, como um heroi de conduta exemplar que serve como modelo para a formação dos jovens, deixa uma lacuna quanto à relação do heroi com o mundo dos mortos. Héracles é apresentado para os etruscos como guia e protetor na viagem ao submundo: conhecia os caminhos do Hades, a métis do ir e vir pelo mundo dos mortos, como demonstrou ao concluir a façanha de captura do cão Cérbero.

\section{Ficha técnica dos vasos:}

(As informações que se seguem foram baseadas nos catálogos de R. Bonaudo (2008), V. Callipolitis (1954), J. M. Helmerijk (1984) e, também, nas informações do Museu do Louvre contidas em seu sítio na rede eletrônica).

1. Héracles, Cérbero e Euristeu. Paris (Louvre) inv.: E701

Proveniência: proximidades de Cerveteri

Material: argila

Dimensões: altura: $42 \mathrm{~cm}$; largura: $41,5 \mathrm{~cm}$; dimensão do friso: $16 \mathrm{~cm}$.

Técnica: figuras negras

Autoria: Pintor de Águias 
Data: c. 520 a. C.

Bibliografia: Catálogo Louvre Coleção Campana 2, $\mathrm{n}^{\circ}$ 9; Hemelrijk 1984, p. 14 ss; $\quad$ Bonaudo, 2004.cat.4, p. 258; CVA:1007816, Callipolitis, 1954, Santangelo, 1959; Plaoutine, 1942.

Descrição geral: Friso central A: Héracles portando a pele de leão e a clava traz o cão de três cabeças, Cérbero, à Euristeu, que se esconde, assustado dentro de um pithus. B: Duas águias voando em ataque a uma lebre.

Orla: linguetas com cores alternadas;

Borda superior: sem ornamentação;

Pescoço: roseta com cruz estrelada ao centro;

Ombro: linguetas com cores alternadas;

Alças: base terminada em palmetas de folhas com cores alternadas;

Friso inferior: alternando flores de lótus e palmetas;

Pés: linguetas de cores alternadas.

2. Héracles, Cérbero e Euristeu. Roma (Vila Giulia) inv.: 50649.

Proveniência: Cerveteri

Material: argila.

Dimensões: altura: 44,4 cm; largura: $41 \mathrm{~cm}$; dimensão do friso: 13,2 cm.

Técnica: figuras negras.

Autoria: indeterminada.

Data: c. 520 a. C.

Bibliografia: Callipolitis, 1954; Hemelrijk, 1984, 23 ss; Bonaudo, R, 2004, p 265; Santangelo, 1959; Plaoutine, 1942.

Descrição: friso central A: Héracles portando a pele de leão e a clava traz o cão de três cabeças, Cérbero, à Euristeu, que se esconde, assustado dentro de um pithus. B: Dois cavalos alados empinados antitéticos.

Orla: linguetas com cores alternadas;

Borda superior: corrente de meandros;

Pescoço: cruz de meandros;

Ombro: corrente de folhas de hera e pequenos frutos

Alças: terminadas em palmetas.

Friso inferior: corrente de folhas de hera e

Pés: linguetas de cores alternadas. 


\section{Bibliografia}

BANDINELLI, Ranuccio Bianchi. L'arte etrusca. Milão: Edizioni Ghibli, 2013.

BAYET, Jean. Idéologie et plastique- Hercule funéraire. Roma, Collection de L'Ėcole Française de Rome, Palais Farnèse, 1974, p. 199335 .

BLOCH, Raymond. Recherches sur les religions de l'Italie antique. Genebra: Librarie Droz, 1976.

BONAUDO, Raffaella. La culla di Hermes, iconografia e imagginario delle hydriai ceretane. Roma: L'Erma di Bretschneider, 2004.

CAMPOREALE, Giovannangelo. Gli etruschi. Milão: UTET Libreria, 2011.

CARCOPINO, Jèrôme. Les origines de l'Hercule romain, premier article (Jean Bayet. Les origines de l'Hercule romain). IN: Journal des Savants, abril 1928, p. 157-168. http://www.persee.fr/web/revues/home/prescript/article/jds_00218103_1928_num_4_1_2860.

CARCOPINO, Jèrôme. Les origines de l'Hercule romaine, deuxième et dernier article (Jean Bayet. Les origines de l'Hercule romaine). IN: Journal des Savants, Maio 1928, p. 205-217. http://www.persee.fr/web/revues/home/prescript/article/jds_00218103_1928_num_5_1_2869.

CARPENTER, Thomas Henry. Art and Myth in ancient Grece. Londres: Thames and Hudson, 1991, p. 117-134.

CRISTOFANI, Mauro. L'arte degli etruschi, produzione e consumo. Torino: Giulio Einaudi, 1978.

. I greci in Etruria, IN: Mode de contacts et processes de transformation dans les sociètes anciènnes. Pisa: EFR, 1983, p.239- 255. 
CUMONT, F. Jean Bayet. Les origines de l'Hercule romain ; ld. Herclè, Etude critique des principaux monuments relatifs à l'Hercule étrusque. In: Revue Belge de Philologie et d'Histoire, 1927, Volume 6, n. ${ }^{\circ} 3$, p. $899-900$

GRIMAL, Pierre. Dicionário da Mitologia Grega e Romana. Rio de Janeiro: Bertrand Brasil, 2005.

. História de Roma. São Paulo: Editora UNESP, 2011.

HEMELRIJK, Jaap Markus. Caeretan Hydriae. Mainz: Zabern, 1984.

. Three caeretan hydriai in Malibu and New York. Malibu: J. Paul Getty Museum, Volume 6, 2000.

PALlOTINO, Massimo. Civiltà Aristica Etrusco- Italica. Florença: Sansoni Editore Nuova SpA, 1985.

PLAOUTINE, Nicolas. La reprèsentation de Thersite par le paintre des hydries dites de Caerés et les sources littéraires qui ont inspiré cet artist. IN: Revue des Études Grecques, tomo 55, fascículo 261-261, julhodezembro 1942 , p. 161-189. http://www.persee.fr/web/revues/home/prescript/article/reg_00352039_ 1942_num_55_261_2955.

POLETTI, Luigi. Osservazione intorno alle tombe etrusche di Cere. IN: Annali dell'Instituto di Corrispondenza Archeologica, Volume 7, 1835.

SANTANGELO, Maria. Idrie Ceretane, 1959. Disponível em: http://www.treccani.it.

MUSEU do LOUVRE: http://www.louvre.fr/

Recebido em: 15/06/2015 Aceito em: 14/08/2015 